\title{
Mitochondrial DNA Haplogroups Observed in Iraqi Population
}

\author{
Nihad A.M. Al-Rashedi ${ }^{1}$, Mohammed A. Jebor ${ }^{2}$, Talib AH Mousa ${ }^{3}$, Ali H. Al-Saadi ${ }^{4}$ \\ ${ }^{1,3}$ Science College- Muthanna University; \\ ${ }^{2,4}$ Science Colleges- Babylon University
}

\begin{abstract}
Mitochondrial DNA hypervariable regions I and II of control region were sequenced from 100 random healthy unrelated individuals of three sequential generations belong to the Arab ethnic of Iraqi population. The aim of this study was to detection the mtDNA haplotypes and classifying it into mtDNA haplogroups will be useful in forensic genetics applications and determining the Iraqi population history. The sequence variation within D-loop control region were analyzed the composition of haplogroups that showed high frequency of haplogroups $U, H, J, M, D, T$ and $N(18 \%, 14 \%, 10 \%, 9 \%, 7 \%, 7 \%$ and $7 \%$, respectively, moderate frequency of haplogroups $L$ and $I$ was (4\%) and B, A, R and $K(2 \%)$, and low frequency of haplogroup pre-HV (1\%). This study was indicated lack of $V, P, Y, X, O, Z, Q, G, E$ and $C$ haplogroups.
\end{abstract}

Keywords: mitochondrial DNA, haplogroups, DNA Sequencing, Arabic Iraqi population

\section{Introduction}

Iraq is located in the Middle East which bordered by Saudi Arabia, Iran, Jordan, Kuwait and Turkey. The Iraqi population consists of $75-80 \%$ Arabs and $20-25 \%$ others. Each population has a unique genetic structure which is determined by the frequency of particular sequence in a population. The frequency of variation in mtDNA D-loop regions can be useful tool related to the genetic diversity, human anthropology and forensic applications. Typing mitochondrial DNA specimens taken from various world populations that they classified into groups represent various mitochondrial DNA haplogroups refers from letter A to $\mathrm{Z}$ according to date their discovery based on the patterns to specific polymorphic nucleotides (1). Haplogroups are reflecting the genetic relationships and branch points on the mitochondrial phylogenetic tree through trace of maternal inheritance linage, (2). The aim of this study was to analyze the genetic variations of the mtDNA D-loop region for detection of mitochondrial DNA haplogroups in the Iraqi population.

\section{Materials and Methods}

The present study was randomly selected hundred blood samples of unrelated Iraqi volunteers of three sequential generations. Mitochondrial DNA was isolated by using mtDNA extraction Kit (Biovision, USA). PCR amplification of the mtDNA D-loop region generates four partially overlapping PCR amplicons ( 350 bp for each one) spanning the four hypervariable fragments ranging from 15997- 16236, 16159-16527, 29- 285 and 172- 419 nucleotide position in the mtDNA D-loop; the four amplified products were subjected to cycle sequencing by using ABI 3730 xL DNA analyzer (Applied Biosystem, USA). The DNA Sequence Data were analyzed by using BioEdit Software and then aligned with the revised Cambridge Reference Sequence (GenBank sequence NC_012920) by added the CLUSTAL W to the same software. Analysis of mtDNA haplogroup by using mtDNAmanager is a web-based bioinformatics resource; find it http://mtmanager.yonsei.ac. $k r$ that enables automatically estimate the most mtDNA haplogroups according to control-region mutation variations and scanning of similar sequences from the database which includes over mtDNA control region sequences of worldwide populations.

\section{Results and Discussion}

The mtDNA sequencing results indicate that variations within D-loop region which defined the $\mathrm{U}, \mathrm{H}, \mathrm{HV}, \mathrm{J}, \mathrm{M}, \mathrm{T}$, I, L3, K, B, and pre-HV haplogroups based on mtDNA manger haplogroups software which distributed each haplogroup represents a sample that attributed to the specific polymorphisms. Distribution of haplogroups in Arabic Iraqi population has clarified the incidence of haplogroup $U$ is $(18 \%)$ in the range of those observed in both previous Iraqi studies and studies of Trans-Caucasian and European populations as shown in table (1). The mtDNA haplogroups $\mathrm{U}$ and $\mathrm{H}$ have high frequency in Iraq (3) according to this study, the Iraqi DNA mitotype belongs to the highly derived recent gene flow from Europe which may be as result of connection with these populations. This current study shows haplogroup $\mathrm{H} 14 \%$ of total Arabic Iraqi samples which included different nucleotide polymorphisms in each haplogroup. There are two studies conducted on mtDNA control region of Iraqi population, one has approximate frequency $(16.9 \%)$ of haplogroups $\mathrm{H}(4)$, while the second study is higher record $19.9 \%$ of haplogroups $H$ (5). The frequency of haplogroup $\mathrm{H}$ is $14 \%$ compared with Iranian $17.7 \%$ and Arabian Peninsula (12.9\%) population (6), so considering an incidence of haplogroup $\mathrm{H}(14 \%)$ is much lower than in Europeans frequency $(33-50 \%)$ but equal to incidence in central Asians (14\%) as shown in table (1).

The analysis of the composition of mtDNA haplogroups that show $10 \%$ haplogroup HV (sub-haplogroup HV1) in this study that considering sub-haplogroup HV1 $10 \%$ is high frequency than Basheer study $6.4 \%$ (4), but it has approximate frequency of $10.6 \%$ in Al-Zahery Study(5). This frequency of sub-haplogroup HV1 is comparable to haplogroups of Iranian and Middle Eastern population, it 


\section{International Journal of Science and Research (IJSR) ISSN (Online): 2319-7064 \\ Index Copernicus Value (2013): 6.14 | Impact Factor (2014): 5.611}

shows substantially differs from that $3.6 \%$ observed in the Arabian Peninsula (Saudi Arabia) but in same study Arabian Peninsula achieved $15.2 \%$ of sub-haplogroup preHV which was much higher than $1 \%$ this study (6) as shown in table (1). The major determinant of mtDNA Middle East is presence of haplogroups $\mathrm{H}, \mathrm{HV}$ and pre-HV. In the European populations frequency of $\mathrm{H}$ and $\mathrm{HV}$ reaches its highest, whereas pre-HV mtDNA has less value. The human mitochondrial sequence of Cambridge reference sequence (CRS) belongs to haplogroup $\mathrm{H}$ subclade $\mathrm{H} 2 \mathrm{a} 2 \mathrm{a}$ which is a descendant of haplogroup HV, so that the high frequency of haplogroups pre-HV and HV in both Arabic population (18.8\%) and in the Arabian Bedouins (20.6\%) shows lowest values of haplogroups $\mathrm{H}$ (7). These studies support the idea that haplogroup $\mathrm{H}$ originated in the Middle East in spite of it being less frequent $t$ in Europe, it shows greatest heterogeneity (8). The haplogroups HV, which connect between Iraqi and Iranian populations and different distribution from other Middle East populations, is main reason to the distribution of haplogroup $\mathrm{HV}$ and partially to the haplogroup $U$ (9). The mtDNA haplogroups $\mathrm{M}(9 \%)$ and B $(2 \%)$ are recorded in this study, haplogroup $\mathrm{M}$ is found at high frequency in central Asia and that may be due to gene flow from Central Asia, whereas the presence of haplogroups L (4\%) signature mtDNA haplogroups goes back to the gene flow from African. Haplogroup $\mathrm{L}$ is regarded as macrohaplogroup and the root of the mitochondrial phylogenetic tree; also it represents the African mitochondrial origin for all humanity. Its origins are connected to mitochondrial Eve, and thus African origins are suggested to be modern humanity (10). The mtDNA Haplogroup $\mathrm{J}$ frequency represent $10 \%$ of total samples. This frequency was higher than that mentioned in both previous examined Iraqi populations but less than that in Iranian. The study observed haplogroups frequencies in Iraqi population: D $(8 \%)$ and $\mathrm{T}$ $(7 \%)$. The presence or absence of specific haplogroups suggests that the gene flow to Iraqi population originates from multiple regions: Europe, Central Asia and Africa, so that, in this study lack of haplogroup V is observed in Iraqi population suggests that the gene flow is undoubtedly from Europe as reported by Torroni and Basheer $(9,4)$. However, $\mathrm{K}$, L1 and L3, are uncommon with average frequency between $1-3 \%$ as illustrated in (Table 1).

In conclusion, this study confirms that Iraqi population share similar characteristics to the West Asian population the European populations and far distant from Central Asian population.

Table 1: Mitochondrial DNA haplogroups frequency in Iraqi and different populations

\begin{tabular}{|c|c|c|c|c|c|c|c|c|c|c|c|c|c|c|c|c|c|c|c|c|}
\hline \multirow{2}{*}{$\begin{array}{l}\text { Population/ } \\
\text { region }\end{array}$} & \multirow{2}{*}{$\begin{array}{c}\text { Sample } \\
\text { size }\end{array}$} & \multicolumn{19}{|c|}{ Haplogroup Frequency \% } \\
\hline & & Pre-HV & $\mathrm{HV}$ & $\mathrm{H}$ & $\mathrm{U}$ & $\mathrm{J}$ & $\mathrm{M}$ & $\mathrm{T}$ & I & $\mathrm{K}$ & $\mathrm{B}$ & L1 & L3 & $\mathrm{W}$ & $\mathrm{X}$ & $\mathrm{V}$ & $\mathrm{N}$ & $\mathrm{D}$ & others & \\
\hline Iraq & 100 & 1 & 10 & 14 & 18 & 10 & 9 & 7 & 4 & 2 & 2 & 1 & 3 & - & - & - & 7 & 7 & 8 & This study \\
\hline Iraq & 153 & - & 6.4 & 16.9 & 15.3 & 8.06 & 8.1 & 3.22 & 1.61 & 12 & 3.22 & - & 4 & 8.87 & - & - & - & - & 11.52 & Basheer et al, 2013 \\
\hline Iraq & 216 & 4.2 & 10.6 & 19.9 & 19 & 9.3 & 1.4 & 8.8 & 1.9 & 3.2 & 0.9 & 1.4 & - & 1.9 & 2.8 & 0.5 & - & - & 11.5 & Al-Zahery et al, 2003 \\
\hline Iran & 415 & 5.5 & 5.5 & 17.1 & 21.5 & 13.5 & NR & 8.4 & 2 & 7.5 & NR & $\mathrm{NR}$ & 2.2 & 2 & 2.9 & - & - & - & 8.6 & Kivisild et al., 2003 \\
\hline Arabia & 389 & 3.6 & 3.6 & 12.9 & 10.5 & 20.8 & NR & 4.6 & 0.8 & 3.6 & NR & NR & 10.5 & 1.8 & 1.8 & - & - & - & 6.2 & Kivisild et al., 2003 \\
\hline Syria & 69 & 4.3 & 4.3 & 24.6 & 15.9 & 10.1 & 1.4 & 10.1 & - & 4.3 & - & 2.9 & - & 2.9 & - & 2.9 & - & - & 11.6 & $\begin{array}{c}\text { Richards \& } \\
\text { Macaulay, 2000 }\end{array}$ \\
\hline Palestinian & 117 & 1.7 & 1.7 & 30.8 & 7.6 & 9.4 & 1.7 & 12.8 & - & 6.8 & - & 0.9 & - & 2.6 & 3.4 & - & - & - & 15.4 & $\begin{array}{c}\text { Richards \& } \\
\text { Macaulay, 2000 }\end{array}$ \\
\hline Georgian & 139 & 7.2 & 7.2 & 17.3 & 21.6 & 3.6 & 2.9 & 12.9 & 2.2 & 10.1 & - & - & - & 1.4 & 10.1 & 0.7 & - & - & 9.3 & Tambets et al, 2000 \\
\hline American & 192 & 7.3 & 7.3 & 30.9 & 22.5 & 8.9 & - & 11.5 & 1.6 & 7.9 & 0.5 & - & - & 1 & 2.1 & - & - & - & 5.3 & Tambets et al, 2000 \\
\hline Anatolia & 388 & 3.6 & 3.6 & 25 & 19.3 & 10.9 & 4.4 & 11.9 & 2.3 & 5.9 & - & NR & 0.3 & 3.9 & 4.4 & - & - & $1^{-}$ & 4.5 & $\begin{array}{l}\text { Kivisild et al., 2003; } \\
\text { Tambets et al, 2000 }\end{array}$ \\
\hline Italian & 99 & 2 & 2 & 33.3 & 22.2 & 7.1 & - & 9.1 & 4 & 8.1 & - & - & - & 2 & 3 & 5.1 & - & - & 4.1 & Torroni et al, 2003 \\
\hline Slav & 324 & NR & NR & 41.4 & 19.4 & 10.5 & 0.9 & 12.3 & 2.8 & 3.7 & - & - & - & 0.9 & 0.6 & 3.1 & - & - & 4.4 & Kivisild et al., 1999 \\
\hline Finno-Ugri & 149 & NR & NR & 45.6 & 22.8 & 12.1 & 0.7 & 6 & 1.4 & 3.3 & - & - & - & 2.7 & 2 & 2 & - & - & 1.4 & Kivisild et al., 1999 \\
\hline German & 200 & NR & NR & 50 & 13.5 & 7.5 & - & 8.5 & 2.5 & 6.5 & - & - & - & 1 & 0.5 & 2.5 & - & - & 7.5 & Lutz et al., 1998 \\
\hline C-Asian & 205 & NR & NR & 14 & 8 & 2.5 & 38.5 & 3.5 & 1 & 0.5 & 6.8 & - & - & 1 & - & - & - & - & 24.2 & Comas et al., 1998 \\
\hline Indian & 1300 & 0.6 & 0.6 & 2.4 & 12 & 0.8 & NR & 1.1 & 0.6 & 0.2 & NR & - & - & 1.5 & 0.2 & - & - & - & 13.8 & Kivisild et al., 2003 \\
\hline
\end{tabular}

NR: not reported

\section{References}

[1] Wallace, D. C.; Brown, M.D. and Lott, M.T. (1999). Mitochondrial DNA variation in human evolution and disease. Gene; 238:211-230

[2] Ruiz-Pesini, E.; Mishmar, D.; Brandon, M.; Procaccio, V. and Wallace, D.C. (2004). Effects of purifying and adaptive selection on regional variation in human mtDNA. Science, 303 (5655):223-226.

[3] Macaulay, V; Richards, M; Hickey, E; Vega, E; Cruciani, F; Guida, V; Scozzari, R; Bonne-Tamir, B; Sykes, B; and Torroni A.(1999). The emerging tree of West Eurasian mtDNAs: a synthesis of control-region sequences and RFLPs. An. J. Hum. Genet.; 64: 232-249.

[4] Basheer, I. Azzawi B.I.; Oleiwi, A.A.; Darweesh, M.A.; Jaradat ; S. and Al-Zaag, A. (2013) Mitochondrial Genome Variation within Iraqi Population. International Journal for Sciences and Technology ; 8 (3):23-27

[5] Al-Zahery , N; Semino, O; Benuzzi, G; Magri, C.; Passarino, G.; Torroni, A. and Santachiara-Benerecetti, A.S. (2003) Y-chromosome and mtDNA polymorphisms in Iraq, a crossroad of the early human dispersal and of post-Neolithic migrations. Mol Phylogenet Evol; 28(3):458-72.

[6] Kivisild, T; Rootsi, S; Metspalu, M; Metspalu, E; Parik, J; Katrin, K; Usanga, E; Mastana, S; Papiha, SS; and

\section{Volume 4 Issue 12, December 2015}




\section{International Journal of Science and Research (IJSR) \\ ISSN (Online): 2319-7064}

Index Copernicus Value (2013): 6.14 | Impact Factor (2014): 5.611

Villems, R. (2003). Genetics of the language and farming spread in India. In: Renfrew $\mathrm{C}$; Boyle $\mathrm{K}$. (Eds.). McDonald Institute Monographs series. Cambridge. UK. Cambridge. 7- Di Rienzo, A; and Wilson, A.C. (1991). Branching pattern in the evolutionary tree for human mitochondrial DNA. Proc. Natl. Acad. Sci. USA 88:1597-1601.

[7] Torroni A, Huoponen K, Francalacci P, Petrozzi M, Morelli L, et al. (1996) Classification of European mtDNAs from an analysis of three European populations. Genetics 144: 1835-1850.

[8] Torroni, A.; Bandelt, H.J.; Macaulay, V.; Richards, M.; Cruciani, F.; Rengo, C.; Martinez-Cabrera, V.; Villems, R.; Kivisild, T.; Metspalu, E.; Parik, J. et al. (2003). A signal from human mtDNA of postglacial recolonization in Europe. Am. J. Hum. Genet. 69:844852

[9] Gonder, M; Katherine, HM; Reed, FA; de Sousa, A; and Tishkoff, S.A.(2006). WholemtDNA Genome Sequence Analysis of Ancient African Lineages. Molec. Biol. Evol. 24(3):757-768. 